\title{
Concentration-Dependent Diversification Effects of Free Cholesterol Loading on Macrophage Viability and Polarization
}

\author{
Xiaoyang Xu Aolin Zhang Ningjun Li Pin-Lan Li Fan Zhang \\ Department of Pharmacology \& Toxicology, Medical College of Virginia, Virginia Commonwealth \\ University, Virginia, Richmond, USA
}

\section{Key Words}

Free cholesterol • Macrophages • Viability • Polarization • Apoptosis • Cyclin E1 • PPARY

\begin{abstract}
Background/Aims: The accumulation of free cholesterol in atherosclerotic lesions has been well documented in both animals and humans. In studying the relevance of free cholesterol buildup in atherosclerosis, contradictory results have been generated, indicating that free cholesterol produces both pro- and anti-atherosclerosis effects in macrophages. This inconsistency might stem from the examination of only select concentrations of free cholesterol. In the present study, we sought to investigate the implication of excess free cholesterol loading in the pathophysiology of atherosclerosis across a broad concentration range from (in $\mu \mathrm{g} / \mathrm{ml}$ ) 0 to 60 . Methods: Macrophage viability was determined by measuring formazan formation and flow cytometry viable cell counting. The polarization of M1 and M2 macrophages was differentiated by FACS (Fluorescence-Activated Cell Sorting) assay. The secretion of IL-1 $\beta$ in macrophage culture medium was measured by ELISA kit. Macrophage apoptosis was detected by flow cytometry using a TUNEL kit. Results: Macrophage viability was increased at the treatment of lower concentrations of free cholesterol from (in $\mu \mathrm{g} / \mathrm{ml}$ ) 0 to 20 , but gradually decreased at higher concentrations from 20 to 60 . Lower free cholesterol loading induced anti-inflammatory M2 macrophage polarization. The activation of the PPARY (Peroxisome Proliferator-Activated Receptor gamma) nuclear factor underscored the stimulation of this M2 phenotype. Nevertheless, higher levels of free cholesterol resulted in pro-inflammatory M1 activation. Moreover, with the application of higher free cholesterol concentrations, macrophage apoptosis and secretion of the inflammatory cytokine IL-1 $\beta$ increased significantly. Conclusion: These results for the first time demonstrate that free cholesterol could render concentration-dependent diversification effects on macrophage viability, polarization, apoptosis and inflammatory cytokine secretions, thereby reconciling the pros and cons of free cholesterol buildup in macrophages to the pathophysiology of atherosclerosis.

X. Xu and A. Zhang contributed equally to this work.

Fan Zhang, Ph.D.

KARGER 125
Department of Pharmacology and Toxicology, Medical College of Virginia, Virginia Commonwealth University, McGuire Hall Annex, Rm 324D, 1112 East Clay St., Richmond, VA 23298, (USA)

Tel. +1 804828 8396, Fax +1 804828 4794, E-Mail fzhang2@vcu.edu 


\section{Cellular Physiology Cell Physiol Biochem 2015;37:419-431 \\ \begin{tabular}{l|l} 
and Biochemistry Published online: August 28, 2015 & $\begin{array}{l}\text { C) 2015 S. Karger AG, Basel } \\
\text { www.karger.com/cpb }\end{array}$ \\
\hline
\end{tabular} \\ Xu/Zhang/Li/Li/Zhang: Free Cholesterol and Macrophage Viability and Polarization}

\section{Introduction}

In atherosclerosis, oxLDL (oxidized Low-Density Lipoprotein) is taken up by lesional macrophages through scavenger receptors such as scavenger receptor class A and CD36 (Cluster of Differentiation 36) and then delivered to endo/lysosomes [1, 2], where the cholesteryl ester is hydrolyzed to free cholesterol. Under normal conditions, the resultant free cholesterol could be reversely mobilized out of macrophages by ATP-binding cassette transporters A1, G1, B4 or SR-BI (Scavenger Receptor class B type I) or re-esterified via ACAT1 (acyl-coenzyme A:cholesterol acyltransferase 1) to cholesteryl ester and stored as cytoplasmic lipid droplets [3-5]. Disturbances in cholesterol metabolism and trafficking could induce both free cholesterol and cholesteryl ester accumulation in macrophages. Biochemical analyses of cholesterol components from atherosclerotic lesions at various stages of development reveal that little to no free cholesterol accumulates in the initial fatty streak phase, but this un-esterified cholesterol steadily increases with atheroma advancement in both animals and humans while cholesteryl ester gradually decreases[6-8]. The significant accumulation of free cholesterol in resident macrophages from advanced atherosclerotic lesions has been well documented [9-11]. Whereas cholesteryl ester is exclusively deposited as lipid droplets in macrophages and produces a foam cell morphology [12,13], free cholesterol accumulates at various locations along the free cholesterol trafficking pathway, such as the lysosomal lumen, plasma membrane, mitochondria and endoplasmic reticulum membranes [14], and the cytoplasm as crystal precipitates [15]. Given that plasma membrane integrity and proper functioning of subcellular organelles are prerequisites for maintaining normal cell operation, excessive incorporations of free cholesterol into subcellular constituents will exert significant adverse effects on macrophage viability [16-18]. As well, a number of studies have shown that free cholesterol promotes inflammation and leads to macrophage apoptosis via mechanisms associated with cell membrane Fas activation [19] and mitochondria [20] or endoplasmic reticulum-induced programed cell death [8]. These findings are consistent with observations of increased macrophage apoptosis and necrosis in advanced atherosclerotic lesion cores.

However, other studies have demonstrated that free cholesterol prevents macrophages from expressing inflammatory-response genes [21,22]. It has been found that free cholesterol buildup elevates desmosterol, an intermediate metabolite in cholesterol biosynthesis. This desmosterol serves as a ligand to initiate the LXR (Liver X Receptor)-mediated signaling cascade, which in turn suppresses inflammatory-response cytokines, including IL-1 $\beta$, CXCL 9 [Chemokine (C-X-C motif) Ligand 9], and CXCL 10, and blunts TLRs (Toll-Like Receptors) inflammatory signaling [23]. These results suggest that free cholesterol accumulation suppresses rather than promotes inflammation in macrophages and has protective effects against atherogenesis.

It is noteworthy that only limited concentrations of free cholesterol were examined in drawing these pro- and anti- inflammatory conclusions. Given that the buildup of cholesterol in macrophages plays a major role in atheroma development, the pathophysiological significance of free cholesterol to macrophages in atherosclerosis should be examined across a broad concentration range. The present study was designed to investigate the effects of free cholesterol accumulation on macrophage viability, pro-inflammatory M1 and anti-inflammatory M2 macrophage polarization, and inflammatory cytokine secretion in a wide free cholesterol concentration setting. We found that at lower concentrations free cholesterol increased macrophage viability and M2 macrophage polarization; while at higher concentrations, free cholesterol led to increased M1 activation, IL- $1 \beta$ secretion, and macrophage apoptosis. These results indicate that free cholesterol has concentrationdependent diversification effects in the pathophysiology of atherosclerosis. Understanding these diversified free cholesterol effects will facilitate the development of cholesteroltargeting approaches for the prevention and treatment of atherosclerosis. 


\section{Cellular Physiology Cell Physiol Biochem 2015;37:419-431

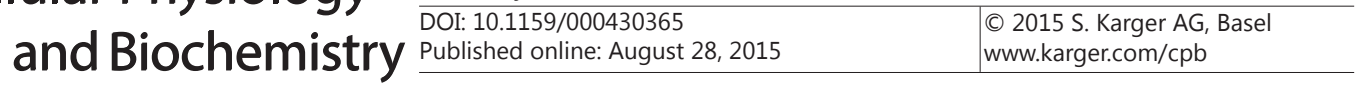 \\ Xu/Zhang/Li/Li/Zhang: Free Cholesterol and Macrophage Viability and Polarization}

\section{Materials and Methods}

\section{Materials}

C57BL/6J mice from Jackson Laboratory were housed on a $12 \mathrm{~h}$ light/dark cycle, ad libitum to normal diet and water. The animal experiment protocol was reviewed and approved by the Institutional Animal Care and Use Committee of Virginia Commonwealth University. Reagents and Biochemical kits were obtained from commercial suppliers as follows: water soluble free cholesterol and filipin (Sigma-Aldrich); premixed WST-1 (Water-Soluble Tetrazolium-1) cell proliferation assay system (Clontech); BODIPY® 493/503 (Life Technologies); Guava ViaCount Reagent, Guava TUNEL (Terminal deoxynucleotidyl transferase dUTP nick end labeling) kit (EMD Millipore); Alexa Fluor® 647 conjugated anti-mouse I-A/I-E and FITC conjugated anti-mouse CD206 (Biolegend); mouse IL-1 beta/IL-1F2 Quantikine ELISA kit (R\&D Systems), PPAR $\gamma$ (Peroxisome Proliferator-Activated Receptor gamma) primary antibody (ABR Affinity BioReagents), cyclin E1 antibody (Bioss), and cyclin E1 siRNA (Santa Cruz Biotechnology); GenMute ${ }^{\mathrm{TM}}$ siRNA Transfection Reagent (SignaGen Laboratories); and $\mathrm{RT}^{2}$ profiler PCR arrays (Qiagene).

\section{Primary Culture of Mouse Bone Marrow-Derived Macrophages}

The collection and differentiation of mouse bone marrow cells into macrophages were conducted following published methods [24, 25]. In brief, mice femur and tibia bones were dissected and their medullary cavities were flushed with RPMI-1640 medium to collect bone marrow cells. After two washes with PBS, the cells were cultured in RPMI-1640 medium supplemented with 15\% L-929 conditional medium, $10 \% \mathrm{FBS}$ and $1 \%$ streptomycin/penicillin; $37^{\circ} \mathrm{C}, 5 \% \mathrm{CO}_{2}$. The identity of differentiated macrophages was confirmed by positive immunostaining of CD68. 12 hours prior to experimentation, the macrophages were gently scraped to make subcultures and the following protocols were applied.

Confocal Microscopy Imaging of Cholesteryl Ester and Free Cholesterol Accumulation

Macrophages were subcultured into 8 -well chamber slides at $2 \times 10^{4}$ cells/well. After $12 \mathrm{~h}$ of free cholesterol treatment, these cells underwent fluorescent staining according to published methods [26, 27]. In brief, the macrophages were fixed in $4 \%$ paraformaldehyde, washed three times in PBS, and then simultaneously treated with bodipy $493 / 503$ and filipin at concentrations of $2.5 \mu \mathrm{M}$ and $50 \mu \mathrm{g} / \mathrm{ml}$, respectively. Fluorescence imaging and visualization were conducted using multiphoton microscopy (Zeiss LMS 510 multiphoton microscope) at $\lambda$ ex/ $\lambda$ em(nm) 485/525 for Bodipy and 740/488 for filipin. Fluorescence intensity was quantified using Image-Pro software as done in our previous study [28].

\section{PCR Array Identification of Cell Cycle-Regulating Genes}

PCR array is a real-time PCR-based gene expression analysis technique that uses a 96-well plate precoated with specific primers of genes of interest. By mixing cDNA templates and PCR reaction components together, the profile of gene expressions could be revealed through real-time PCR cycling reactions. Total RNA from macrophages treated with free cholesterol at $20 \mu \mathrm{g} / \mathrm{ml}$ for $12 \mathrm{~h}$ was extracted with Trizol. The synthesized first strand cDNA was used to constitute the PCR reaction according to the manufacturer's manual. The PCR cycling reactions were conducted as follows: Denaturation at $95^{\circ} \mathrm{C}$ for $15 \mathrm{~s}$ followed by 40 amplification cycles at $95^{\circ} \mathrm{C} \times 15 \mathrm{~s}$ and $60^{\circ} \mathrm{C}$ for $30 \mathrm{~s}$ (CFX connect, BioRad). The expression levels of eightfour genes key to cell cycle regulation were concomitantly examined.

\section{Macrophage Cell Viability Determination by WST Analysis and Viable Cell Counting}

The concentration-dependent effects of free cholesterol on macrophage viability were quantified by measuring the formation of the tetrazolium metabolite formazan [29] and flow cytometry cell counting. Macrophages were split into 96-well plates with $2.5 \times 10^{4}$ cells/well and cultured $12 \mathrm{~h}$ prior to the addition of free cholesterol at the concentrations $(\mu \mathrm{g} / \mu \mathrm{l}) 0,5,10,20,40$ and $60.24 \mathrm{~h}$ later, tetrazolium-containing WST-1 premix was added to the cell culture medium by following the product's manual. After incubation for $1 \mathrm{~h}$ at $37^{\circ} \mathrm{C}$ and $5 \% \mathrm{CO}_{2}$, the formation of the formazan metabolite was determined by colorimetrical absorbance measurement at $\lambda=480 \mathrm{~nm}$ and subtraction of background at $\lambda=605 \mathrm{~nm}$ (FilterMax F3, Molecular Devices). For viable cell counting, macrophage culture and free cholesterol treatments were conducted in the same manner as in the WST assay except that $35 \mathrm{~mm}$-dishes were used. Guava ViaCount reagent was mixed with a plasma membrane-permeable and a plasma membrane-impermeable dye and then applied to 


\section{Cellular Physiology Cell Physiol Biochem 2015;37:419-431 \begin{tabular}{ll|l} 
aOI: 10.1159/000430365 & $\begin{array}{l}\text { O 2015 S. Karger AG, Basel } \\
\text { www.karger.com/cpb }\end{array}$ \\
\hline
\end{tabular} \\ $\mathrm{Xu} /$ Zhang/Li/Li/Zhang: Free Cholesterol and Macrophage Viability and Polarization}

stain free cholesterol-treated macrophages to differentiate viable cells from apoptotic ones; this application was performed according to the product's manual. After incubation for $30 \mathrm{~min}$ at room temperature, cell counting was conducted using the ViaCount module on a Guava EasyCyte flow cytometer.

Macrophage M1/M2 Polarization and Apoptosis Analysis by Flow Cytometry Assay

Free cholesterol-treated macrophages were collected by gentle scraping and centrifugation. After two PBS washes, cell pellets were re-suspended in 0.05\% BSA-supplemented PBS buffer with $1 \times 10^{4}-2.5 \times 10^{5}$ cells $/ 100 \mu \mathrm{l}$ and then incubated with FITC-conjugated CD206(M2 marker) [30,31] antibodies and Alexa Fluor 647 associated I-A/I-E (M 1 maker) [32] antibodies at 1:200 and 1:100, respectively, for $15 \mathrm{~min}$ at $4^{\circ} \mathrm{C}$. The M1 and M2 subpopulations were then sorted out through a BD FACSCanto II flow cytometer [ $\lambda \mathrm{Ex} / \mathrm{Em}$ (nm), 488/525 and 633/647] and analyzed using the BD FACSDiva software. The concentration-dependent effects of free cholesterol on macrophage apoptosis were determined by TUNEL analysis based on the manufacturer's manual. In brief, $5 \times 10^{4}-1.0 \times 10^{5}$ cells per sample were fixed with $4 \%$ paraformaldehyde for $1 \mathrm{~h}$ at $4^{\circ} \mathrm{C}$ and then permeabilized using $70 \%\left(\mathrm{v} / \mathrm{v}\right.$ ) ice-cold ethanol for $2 \mathrm{~h}$ at $4^{\circ} \mathrm{C}$. The BrdUTP was then incorporated into nuclear DNA in a TdT reaction mixture containing TdT enzyme and BrdUTP for 1 $\mathrm{hr}$, followed by anti-BrdUTP immunostaining reaction for $30 \mathrm{~min}$ at $37^{\circ} \mathrm{C}$. The positively stained cells were differentiated using Guava Easycyte flow cytometry.

ELISA Analysis of IL-1 $\beta$ Secretions from Macrophages in Culture

Macrophages were sub-cultured into 6-well plates at $5 \times 10^{5}$ cells/well. $12 \mathrm{~h}$ after free cholesterol treatments, the culture medium was collected for IL-1 $\beta$ quantification with IL-1 $\beta$ ELISA kit according to the manufacturer's instructions and our previous study [33]. In brief, IL-1 $\beta$-containing culture medium was added to a microplate strip, $100 \mu \mathrm{l} /$ well, incubated for $2 \mathrm{~h}$ at room temperature, mixed with IL-1 $\beta$ conjugate, and then incubated for another $2 \mathrm{~h}$ at room temperature. Thorough washes were performed between and after the two incubations. $100 \mu \mathrm{l}$ of substrate solution was applied to generate chemiluminescence. Chemiluminescent absorbance was determined using a microplate reader at (nm) $\lambda=450$, corrected to readings at $\lambda=570$. The IL- $1 \beta$ was quantified by relating the sample readings to the generated standard curve.

Cyclin E1 and PPAR $\gamma$ Expressions by Real-Time PCR and Western Blot Assay

In analyzing cyclin E1 and PPAR $\gamma$, the total RNA and proteins were extracted from macrophages 12 h- and 24 h-post free cholesterol treatments, respectively. The real-time PCR reaction and the Western blot assays were conducted according to our previous methods [34, 35]. The specific primer pairs used for the amplification of cyclin E1 and PPAR $\gamma$ were 5'-GGA AAA TCA GAC CAC CCAGA-3' and 5'-AGG ATG ACG CTG CAG AAAGT-3', and 5'-CTC CGT GAT GGA AGA CCACT-3' and 5'-CAA CCA TTG GGT CAG CTCTT-3', respectively. In Western blot, the cyclin E1 or PPAR $\gamma$ target band was visualized and quantified using an Odyssey Imager with the application of infrared fluorescent IRDye ${ }^{\circledR} 680$ RD-conjugated secondary antibodies.

Statistics

Data were presented as mean \pm SE. Significant differences between and within multiple groups were examined using ANOVA for repeated measures, followed by Duncan's multiple-range test. Student's $\mathrm{t}$-test was used to evaluate the significance in differences between 2 groups of observations. $\mathrm{P}<0.05$ was considered statistically significant.

\section{Results}

Macrophage Free Cholesterol Accumulation upon Free Cholesterol Loading

To determine the effects of free cholesterol loading on cholesterol accumulation in macrophages, filipin and Bodipy 493/503 stainings were conducted to examine free cholesterol and cholesterol ester buildup, respectively. The confocal microscopy filipin images showed that the accumulation of free cholesterol increased across the gamut of the cholesterol concentrations applied, and the distribution of the accumulated free cholesterol changed from a smear pattern to compartmentalization-like aggregation with increased cholesterol loading. In contrast, the buildup of cholesterol ester reached a peak at around 


\section{Cellular Physiology Cell Physiol Biochem 2015;37:419-431

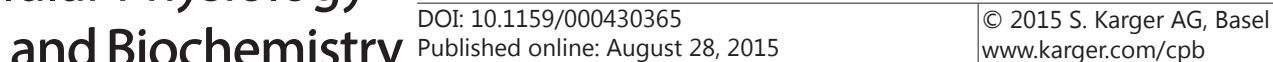

Fig. 1. Accumulation of cholesterol in macrophages upon free cholesterol loading. A: Confocal microscopy images showed that free cholesterol, stained blue by filipin, progressively accumulated in macrophages as applied free cholesterol concentrations increased from (in $\mu \mathrm{g} / \mathrm{ml}$ ) 0 to 60 . As well, free cholesterol deposition changed from a smear pattern to compartmentalization-like aggregation. In contrast, the buildup of cholesteryl ester, stained green by bodipy 493/503, featured an increase and a subsequent decrease with greater cholesterol loading. B and C: Quantification of free cholesterol and cholesteryl ester buildup by fluorescence intensity analysis. $(P<0.05$, * vs. 0 group; \# vs. $20 \mu \mathrm{g} / \mathrm{ml}$ group, $\mathrm{n}=6)$.

$20 \mu \mathrm{g} / \mathrm{ml}$ of free cholesterol and decreased thereafter, as revealed by changes in lipid droplet sizes (Fig. 1A). The accumulation of free cholesterol and cholesteryl ester was quantified by fluorescence intensity analysis of images from the filipin and Bodipy 493/503 stainings [36] (Fig. 1B and 1C).

Concentration-Associated Dual Effects of Free Cholesterol on Macrophage Viability

The accumulation of cholesterol in macrophages and the buildup of lesional macrophages underscore the development of the atheroma. In advanced atherosclerotic lesions, cholesterol-laden apoptotic and necrotic macrophages are confined under a fibrous cap whose rupture can lead to thrombosis and cause acute cardiovascular incidents such as heart attacks and strokes. Given that advanced atheromas are made up of macrophages containing excessive free cholesterol and the significant consequences associated with these atherosclerotic

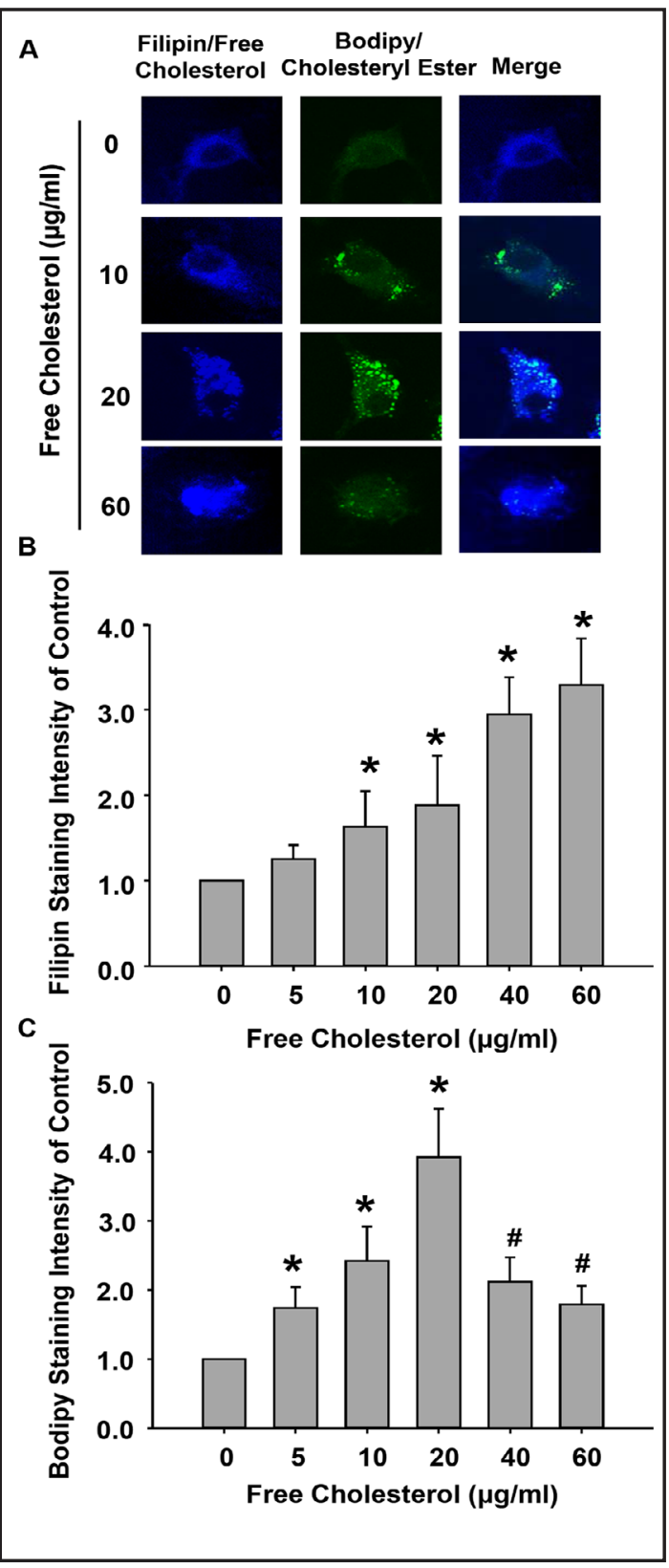
lesions, it is necessary to examine free cholesterol buildup on macrophage viability. Using tetrazolium salt (WST) metabolite assay and direct cell counting flow cytometry, viable macrophages were quantified. WST is a substrate of succinate-tetrazolium reductase, which exists in the mitochondrial respiratory chain and is only metabolically active in viable cells. The absorbance readings for formazan production revealed that relative formazan generation increased from 1 to $1.40 \pm 0.14$ at concentrations $(\mu \mathrm{g} / \mathrm{ml})$ from 0 to 20 but decreased thereafter at higher concentrations to $0.92 \pm 0.08$ ultimately at $60 \mu \mathrm{g} / \mathrm{ml}$ (Fig. 2A); thus, low and high free cholesterol concentrations have opposing effects on macrophage viability. Flow cytometry results also showed that the relative number of viable macrophages was enhanced from 1 to $1.40 \pm 0.32$ but then reduced to $0.81 \pm 0.11$ at the same cholesterol concentrations (Fig. 2B) as mentioned above.

Free Cholesterol Promotes Macrophage Viability through Cyclin E1 Activation

Next, we further investigated the dual effects of free cholesterol on macrophage viability by examining the expression of genes key to cell cycle regulation using PCR array analysis. A 


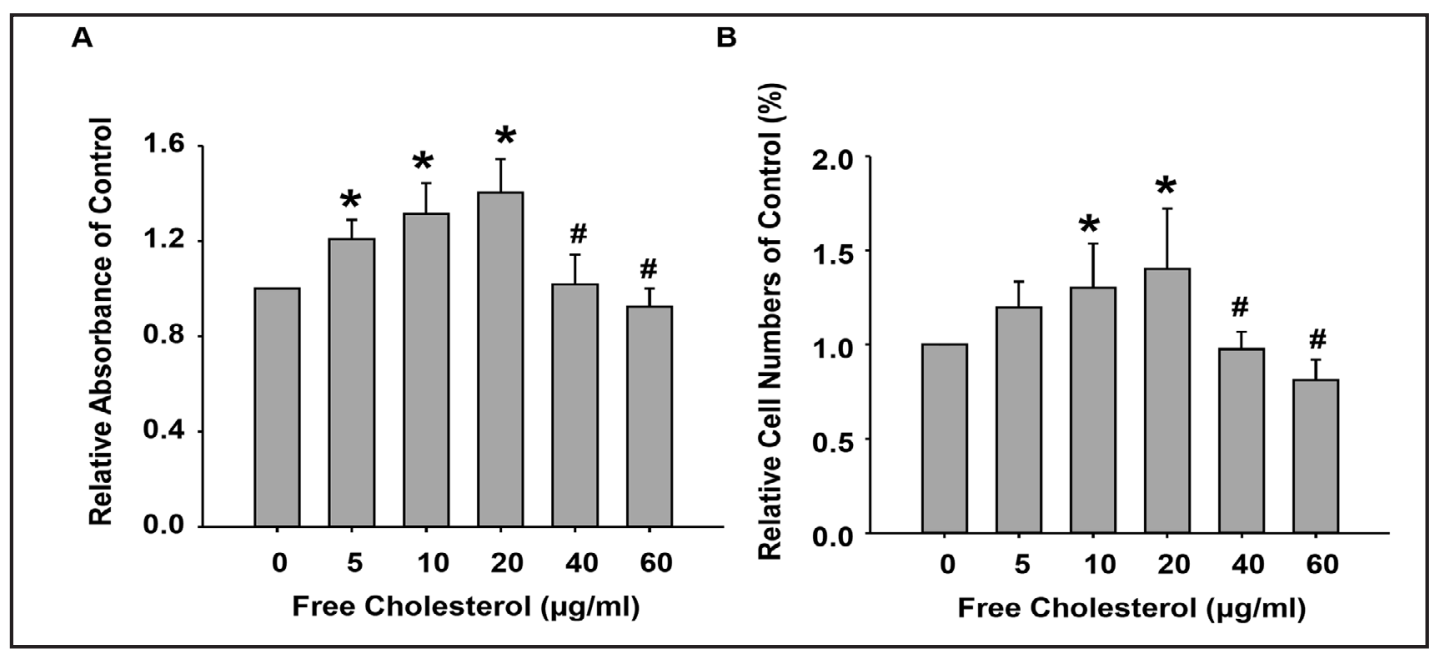

Fig. 2. Concentration-associated dual effects of free cholesterol loading on macrophage viability. A: Absorbance readings showed that the relative production of the formazan metabolite increased from 1.0 in control to $1.40 \pm 0.14$ at $20 \mu \mathrm{g} / \mathrm{ml}$ of free cholesterol and then gradually decreased to $0.92 \pm 0.08$ at $60 \mu \mathrm{g} /$ $\mathrm{ml}$ of cholesterol. B: Flow cytometry readings of relative viable macrophage numbers showed a concentration-associated pattern of change similar to that of formazan metabolite production presented in $A$. $(P<0.05$, * vs. 0 group; \# vs. $20 \mu \mathrm{g} / \mathrm{ml}$ group, $\mathrm{n}=7$ ).

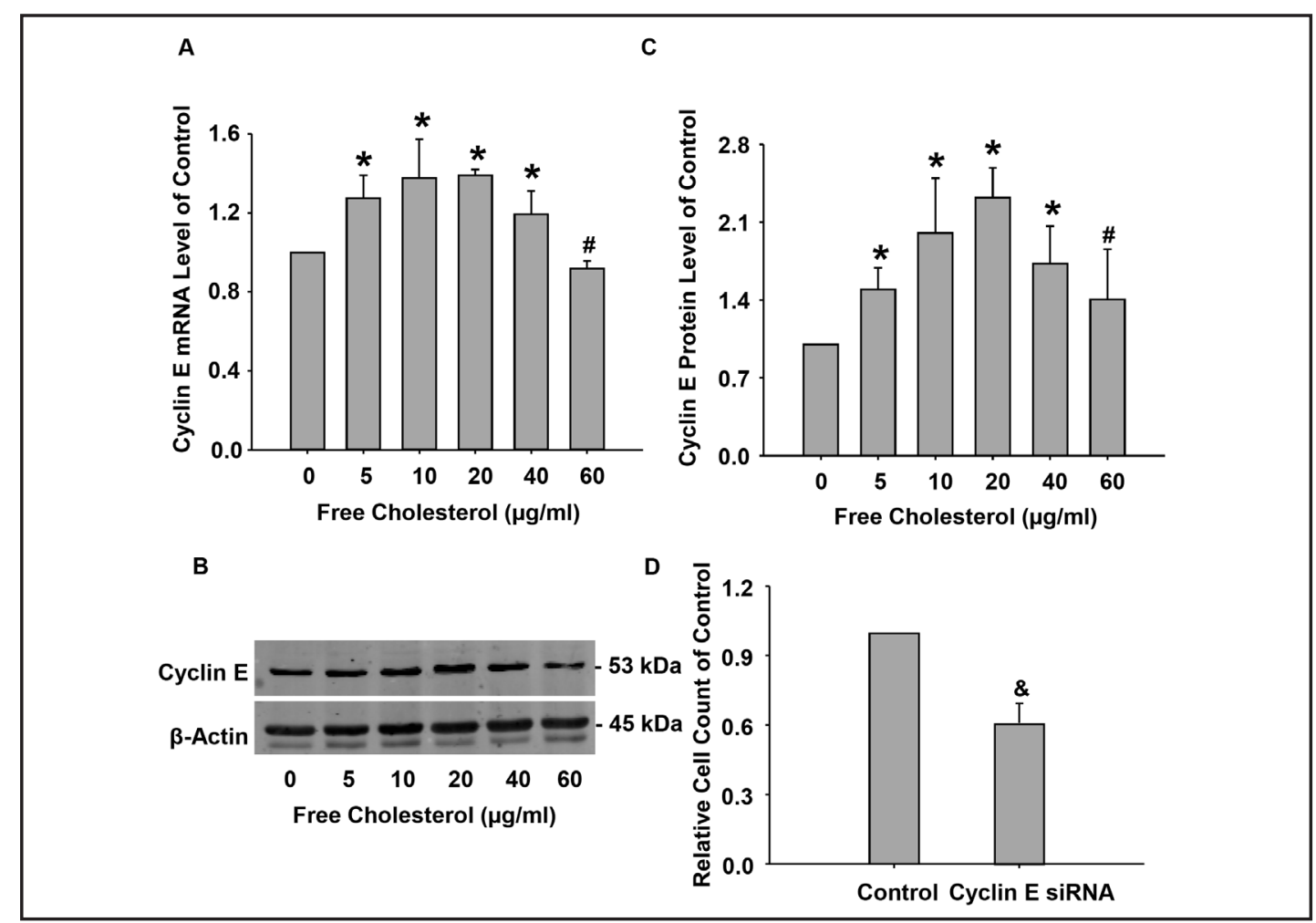

Fig. 3. Effects of free cholesterol loading on cyclin E1 expression in macrophage viability. Free cholesterol concentration-dependently increased and decreased expressions of cyclin E1 mRNA (A) and proteins (B, C). D: Macrophage proliferation at $20 \mu \mathrm{g} / \mathrm{ml}$ of free cholesterol was attenuated by cyclin E1 gene interference as measured by flow cytometry viable cell counting. $(P<0.05, * v s .0$ group, \# vs. $20 \mu \mathrm{g} / \mathrm{ml}$ group, $\mathrm{n}=4$; \& vs. control, $\mathrm{n}=6)$.

cohort of 84 of these genes, whose functions included controlling transitions between cell cycle phases, DNA replication, and checkpoints and arrests, were screened. Among them, 
Fig. 4. Distinguishing $\mathrm{M} 1$ and $\mathrm{M} 2$ polarization upon free cholesterol loading by fluorescence-activated cell sorting (FACS). A: FACS diagram of polarized M1 and M2 subgroup macrophages. B: Summarized FACS results showed that M2 activation was increased at lower concentrations of free cholesterol but markedly reduced at higher concentrations. C: M1 activation experienced significant increases with the application of higher free cholesterol concentrations. $(P<0.05, * v s$. 0 group, \# vs. $20 \mu \mathrm{g} / \mathrm{ml}$ group, $\mathrm{n}=6$ ).

the genes with the most profound changes in expressions included (folds of Ctrl, gene): 1.56, Cyclin D1; 1.73, Cyclin E1; and 1.42, cell division cycle 6 homolog upon $20 \mu \mathrm{g} / \mathrm{ml}$ free cholesterol treatment. Of these genes, the expression of Cyclin E1 displayed the most significant increase and was selected for verification by real-time PCR and Western blot analysis. The results showed that normalized cyclin E1 RNA and protein levels were $1,1.27$ $\pm 0.12,1.38 \pm 0.20,1.39 \pm 0.03,1.19 \pm$ 0.12 , and $0.92 \pm 0.04$ (Fig. $3 \mathrm{~A}$ ) and 1 , $1.47 \pm 0.24,2.00 \pm 0.49,2.32 \pm 0.27$, $1.73 \pm 0.34$, and $1.40 \pm 0.45$ (Fig. $3 \mathrm{C}$ ), respectively, corresponding to free cholesterol concentrations of (in $\mu \mathrm{g} /$ ml) $0,5,10,20,40$, and 60. Figure 3B was a representative image of cyclin
A
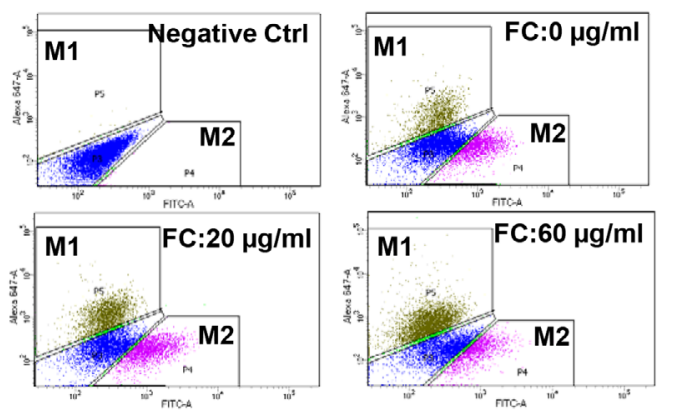

B

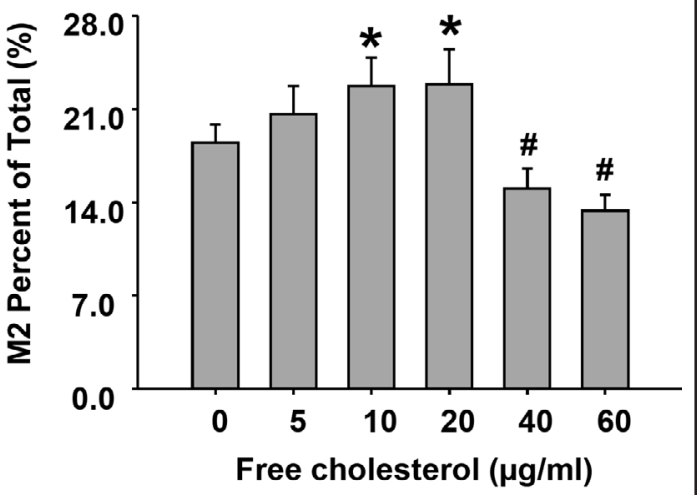

C

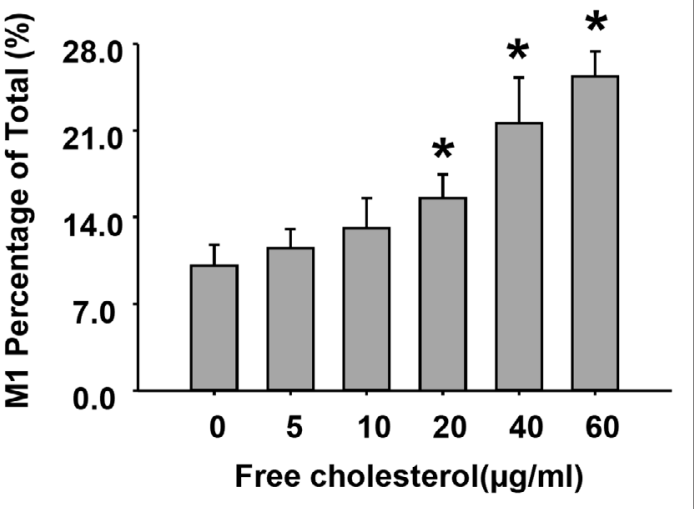

E1 Western blot. Functionally, by blocking cyclin E1 expression, the proliferative effects of cholesterol on macrophages were significantly attenuated as measured by viable cell counting flow cytometry (Fig. 3D).

\section{The Distinct Profile of M1 and M2 Polarization upon Free Cholesterol Loading}

Macrophages are heterogeneous in terms of their polarization. Many studies have demonstrated that both M1-and M2-polarized macrophages dynamically coexist in atherosclerotic lesions [37-39]. Functionally, these two subgroups of macrophages secrete distinct pro- or anti-inflammatory cytokines that have progressive or regressive effects on atherosclerosis. We, therefore, proceeded to determine the effect of free cholesterol buildup on macrophage polarization using fluorescence-activated cell sorting (FACS) assay. Figure 4A was a representative FACS diagram of polarized M1 and M2 populations. The summarized FACS results showed that M2 polarization was boosted from (\%) $18.50 \pm 1.34$ to $22.90 \pm 2.57$ when cholesterol was loaded at low concentrations of (in $\mu \mathrm{g} / \mathrm{ml}$ ) 0 to 20, but was reduced at higher concentrations (Fig. 4B). M1 polarization, however, was enhanced across the gamut of the tested cholesterol concentrations (Fig. 4C).

\section{KARGER}


Fig. 5. Free cholesterol induced the M2 phenotype through the activation of the nuclear factor PPAR $\gamma$. A: The expression of PPAR $\gamma$ mRNA increased with the application of free cholesterol at concentrations from (in $\mu \mathrm{g} / \mathrm{ml}$ ) 0 to $\sim 20$, but gradually decreased thereafter at higher concentrations. B: The representative Western blot image of PPAR $\gamma$ C: The expression of PPAR $\gamma$ proteins upon free cholesterol treatment had a pattern similar to that of the mRNA. D: Inhibiting or silencing PPAR $\gamma$ markedly attenuated M2 activation by free cholesterol at $20 \mu \mathrm{g} / \mathrm{ml}$. $\left(P<0.05,{ }^{*} v s .0\right.$ group, \# vs. control, $\left.\mathrm{n}=6\right)$.

There have been reports that the induction of the M2 phenotype is associated with the activation of the nuclear factor PPAR $\gamma$ [40]. We thus decided to explore the mechanisms underlying free cholesterol-induced M2 stimulation by testing the functional role of PPAR $\gamma$. The results in Fig. 5A and 5C showed that the expressions of PPAR $\gamma$ in mRNA and protein progressively increased with free cholesterol treatment at concentrations from (in $\mu \mathrm{g} / \mathrm{ml}$ ) 0 to 20 , but then gradually decreased with treatment at higher concentrations from (in $\mu \mathrm{g} / \mathrm{ml}$ ) 20 to 60 . Fig. 5B was the representative Western blot image of PPAR $\gamma$. It should be noted that these changes in PPAR $\gamma$ expressions correlated well with M2 activation. siRNA gene interference and pharmacological (GW9662) blocking of PPAR $\gamma$ significantly attenuated M2-boosted effects by free cholesterol at $20 \mu \mathrm{g} / \mathrm{ml}$ (Fig. 5D).

Free Cholesterol Concentration-Dependent Effects on Inflammation and Apoptosis

M1 macrophages secrete pro-inflammatory cytokines that play critical roles in

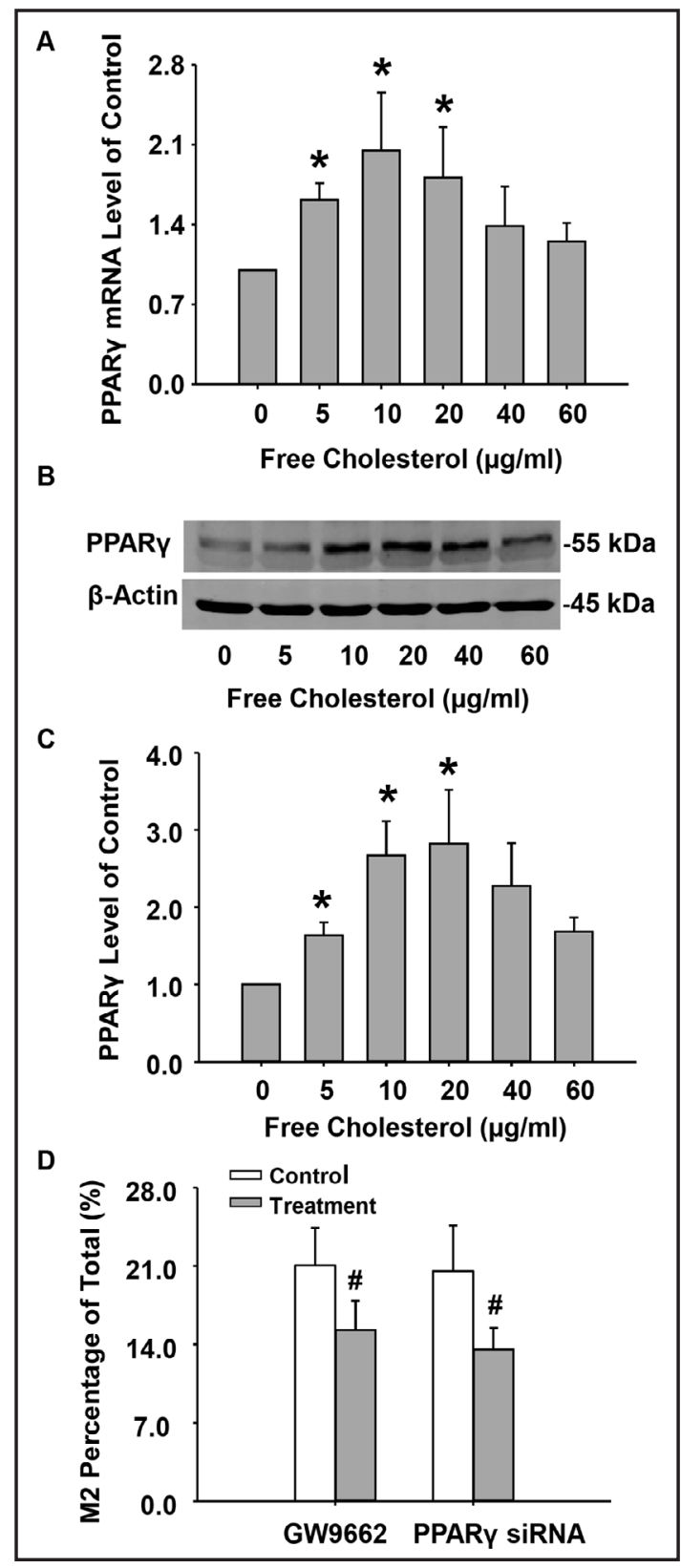
the pathogenesis of atherosclerosis. To elucidate the functional significances of macrophage polarization by free cholesterol, we examined the production of IL-1 $\beta$, a prototypic pro-inflammatory cytokine, and analyzed macrophage apoptosis. The real-time PCR and ELISA analysis results (Fig. 6A and 6B) showed that IL-1 $\beta$ mRNA levels and protein secretions were concurrently enhanced with increases in free cholesterol concentration. Similarly, macrophage apoptosis as measured by TUNEL analysis of DNA integrity was concentration-dependently elevated by free cholesterol. Figure 7A: Flow cytometry diagram of apoptotic macrophages. Figure 7B: TUNEL analysis results showing that the percentage of apoptotic macrophages was markedly increased with the application of high concentrations of cholesterol.

\section{Discussion}

The present study demonstrated that free cholesterol exerts concentration-dependent diversification effects on macrophage viability, polarization, inflammation, and apoptosis. 


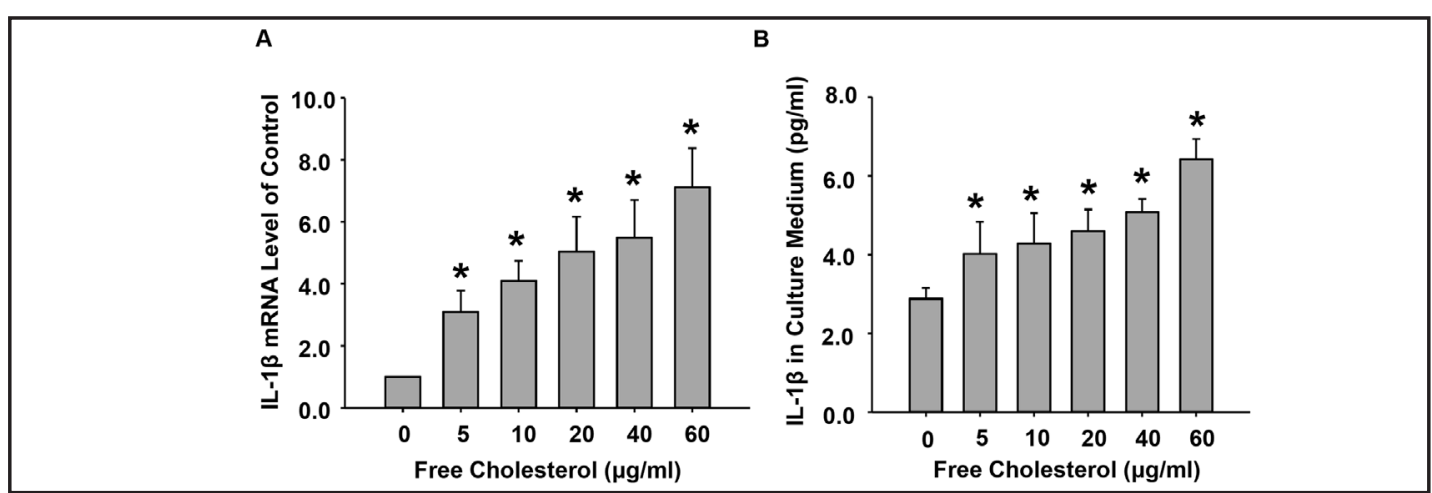

Fig. 6. Free cholesterol loading boosted pro-inflammatory cytokine IL-1expression. A: IL-1 $\beta$ mRNA levels were enhanced with increases in free cholesterol loading. B: ELISA analysis of secreted IL-1 $\beta$ in macrophage culture medium. $(P<0.05, *$ vs. 0 group, $\mathrm{n}=3)$.

Fig. 7. Macrophage apoptosis upon free cholesterol application at high concentrations. A: Flow cytometry diagram of apoptotic macrophages. B: Summarized results showing that the percentage of apoptotic macrophages was markedly increased with the application of high concentrations of cholesterol $(P<0.05$, * vs. 0 group, $\mathrm{n}=7$ ).

Lower concentrations of free cholesterol enhanced macrophage viability and caused anti-inflammatory M2 activation while higher concentrations induced pro-inflammatory M1 activation and led to apoptosis.

Free cholesterol is water insoluble and thus cannot be directly administered for macrophage treatment. In the present study, a vehicle-based cholesterol/methyl- $\beta$-cyclodextrin hydrophilic complex was applied to load free cholesterol into macrophages. This free cholesterol delivery strategy was similar to approaches taken in other studies whe-

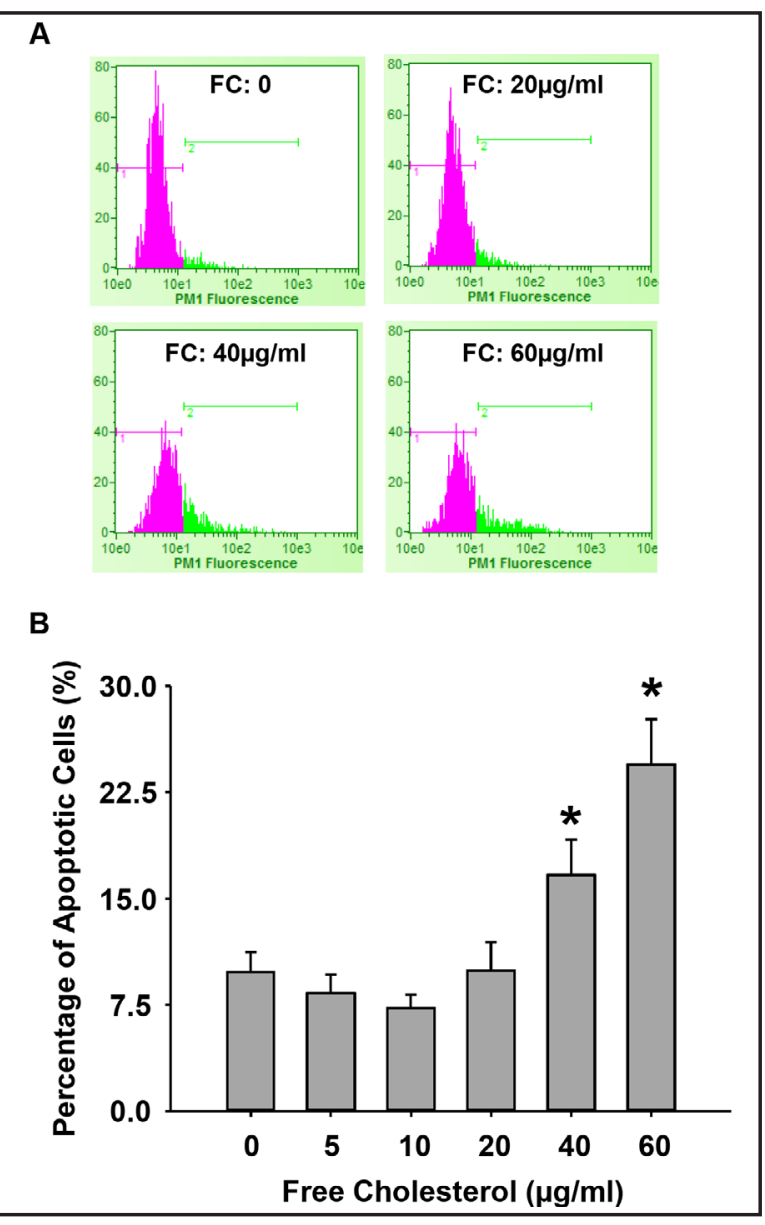
re free cholesterol was used $[23,41,42]$. When free cholesterol was applied to macrophages, free cholesterol accumulation occurred along with the formation of cholesteryl ester-filled lipid droplets. The esterified cholesterol in lipid droplets might mainly stem from the catalysis of partially loaded free cholesterol by ACAT1, a major enzyme responsible for the conversion of free cholesterol to cholesterol ester on the macrophage endoplasmic reticulum. Since free cholesterol buildup underscores macrophage viability and phenotype changes, we sought to determine free cholesterol accumulation rather than quantify the amount of free cholesterol taken up by cells upon treatment. Moreover, we preferred biochemical stainings to chromatographic measurements $[43,44]$ in quantifying free cholesterol buildup because 


\section{Cellular Physiology Cell Physiol Biochem 2015;37:419-431 \\ \begin{tabular}{l|l|l|}
\hline DOI: 10.1159/000430365 & O 2015 S. Karger AG, Basel \\
\hline Published
\end{tabular}

these direct stainings allowed us to visualize the different accumulation profiles between free cholesterol and cholesteryl ester. Using filipin staining, the accumulation of free cholesterol has been determined, revealing that free cholesterol and cholesterol ester accumulation in macrophages followed different patterns: While free cholesterol experienced a steady buildup, the deposition of cholesteryl ester increased to a peak and then gradually decreased as evidenced by shrunken lipid droplet sizes and attenuated Bodipy 493/504 fluorescence intensity. At this point, higher cholesterol concentrations were associated with both reduced bodipy intensity and increased macrophage apoptosis; though, it might be argued it was the enhanced cell death that led to the decrease of Bodipy intensity. In apoptosis as well as necrosis, cell structures are disrupted, such as blebs formation and cell membrane and nucleus disintegration; however, these structural damages have nothing to do with alterations in lipid droplets. Therefore, the examined decrease in Bodipy staining was solely caused by the reduction in cholesteryl ester deposition. It has been reported that free cholesterol loading could disrupt the functions of the endoplasmic reticulum [45], where the esterification of free cholesterol by ACAT1 takes place [8]. These results suggest that different levels of free cholesterol accumulation have profoundly different impacts on macrophages in the pathophysiology of atherosclerosis.

In this study, we investigated the effects of free cholesterol on macrophage viability and polarization within the concentration range of 0 to $60 \mu \mathrm{g} / \mathrm{ml} ; 60 \mu \mathrm{g} / \mathrm{ml}$ was established as the upper limit of this range since higher free cholesterol concentrations cause severe cytotoxicity and result in significant cell death. We found that M2 macrophage polarization increased at lower free cholesterol concentrations to a peak and then gradually decreased at higher concentrations. Our findings were consistent with one study showing that free cholesterol 'deactivated' and suppressed inflammatory-response genes, which implied the induction of the M2 phenotype [23]. It is noteworthy that the concentration of free cholesterol used in the said study ranged from (in $\mu \mathrm{g} / \mathrm{ml}$ ) 0 to 30 , which was close to the concentrations over which M2 activation was observed in our study. Therefore, the induction of the M2 macrophage phenotype by cholesterol was solely associated with the application of low levels of free cholesterol.

There have been reports that the mechanisms underlying the activation of M2 include the Th2-cytokine IL4-associated PPAR $\gamma$ pathway [40] and desmosterol-mediated LXR signaling [23]. In our study, we found that free cholesterol exerted concentrationdependent boosting or inhibitive effects on the expression PPAR $\gamma$ and orchestrated the generation of the M2 phenotype, which represents a novel mechanism for M2 activation. The concentration range of free cholesterol favoring the M2 phenotype was very limited, beyond which significant increases in the M1 phenotype occurred. Consistently, the expression of the pro-inflammatory cytokine IL- $1 \beta$ concurrently increased. It was noteworthy that, at lower concentrations of free cholesterol treatment $(0-20 \mu \mathrm{g} / \mathrm{ml}), \mathrm{IL}-1 \beta$ secretions also experienced some increases. These moderate increases may be associated with slight rises in the number of M1 macrophages at low concentrations of cholesterol treatment. However, these moderate increases were distinctly different from the robust secretions of IL-1 $\beta$ at higher free cholesterol treatment $(20-60 \mu \mathrm{g} / \mathrm{ml})$. These results collectively indicated that higher levels of cholesterol had pro-atherosclerotic effects. These results also agreed with long-standing observations that more accumulated free cholesterol and M1 macrophages were found in advanced atheroma [9-11,46].

Our macrophage viability results showed that the application of low concentrations of free cholesterol increased macrophage viability, which was reflected in macrophage proliferation - an event involved in macrophage accumulation in atherosclerotic lesions [47] - while high concentrations of free cholesterol led to cell apoptosis. Flow cytometry results demonstrated that free cholesterol at lower concentrations increased M2 polarization, but at higher concentrations induced M1 polarization. Therefore, apoptosis might have more profound effects on M2 than M1 macrophages. These described simultaneous events may be behind the concentration-dependent effects of free cholesterol in macrophages in atherosclerosis. There may exist some concerns about TUNEL's inability to distinguish 


\section{Cellular Physiology Cell Physiol Biochem 2015;37:419-431 \begin{tabular}{ll|l} 
and Bor 10.1159/000430365 & $\begin{array}{l}\text { O 2015 S. Karger AG, Basel } \\
\text { www.karger.com/cpb }\end{array}$ \\
\hline
\end{tabular} \\ Xu/Zhang/Li/Li/Zhang: Free Cholesterol and Macrophage Viability and Polarization}

between cell apoptosis and necrosis. However, macrophage death from either apoptosis or necrosis upon high free cholesterol treatment will likely have the same consequences: Reducing the numbers of M2 type macrophages and increasing the numbers of proinflammatory M1 macrophages.

In summary, this study for the first time examined the effects of free cholesterol on macrophage viability and polarization across a broad concentration range. We demonstrated that free cholesterol has concentration-dependent diversification effects on macrophage viability and polarization, thereby reconciling the pros and cons of free cholesterol toward atherogenesis. Understanding these concentration-dependent effects of cholesterol on atherosclerosis will facilitate the development of a free cholesterol-based therapy for preventing and treating atherosclerosis.

\section{Acknowledgements}

This work is supported by NIH grant R01HL115068.

\section{Disclosure Statement}

None declared.

\section{References}

1 Levitan I, Volkov S, Subbaiah PV: Oxidized LDL: diversity, patterns of recognition, and pathophysiology. Antioxid Redox Signal 2010;13:39-75.

2 Collot-Teixeira S, Martin J, Mcdermott-Roe C, Poston R, Mcgregor JL: CD36 and macrophages in atherosclerosis. Cardiovasc Res 2007;75:468-477.

3 Chang TY, Chang CC, Lin S, Yu C, Li BL, Miyazaki A: Roles of acyl-coenzyme A:cholesterol acyltransferase-1 and -2. Curr Opin Lipidol 2001;12:289-296.

4 Brown MS, Goldstein JL: Lipoprotein metabolism in the macrophage: implications for cholesterol deposition in atherosclerosis. Annu Rev Biochem 1983;52:223-261.

5 Maxfield FR, Tabas I: Role of cholesterol and lipid organization in disease. Nature 2005;438:612-621.

6 Katz SS, Shipley GG, Small DM: Physical chemistry of the lipids of human atherosclerotic lesions. Demonstration of a lesion intermediate between fatty streaks and advanced plaques. J Clin Invest 1976;58:200-211.

7 Tabas I: Free cholesterol-induced cytotoxicity a possible contributing factor to macrophage foam cell necrosis in advanced atherosclerotic lesions. Trends Cardiovasc Med 1997;7:256-263.

8 Tabas I: Consequences of cellular cholesterol accumulation: basic concepts and physiological implications. J Clin Invest 2002;110:905-911.

9 Lundberg B: Chemical composition and physical state of lipid deposits in atherosclerosis. Atherosclerosis 1985;56:93-110.

10 Small DM, Bond MG, Waugh D, Prack M, Sawyer JK: Physicochemical and histological changes in the arterial wall of nonhuman primates during progression and regression of atherosclerosis. J Clin Invest 1984;73:1590-1605.

11 Rapp JH, Connor WE, Lin DS, Inahara T, Porter JM: Lipids of human atherosclerotic plaques and xanthomas: clues to the mechanism of plaque progression. J Lipid Res 1983;24:1329-1335.

12 Klinkner AM, Waites CR, Kerns WD, Bugelski PJ: Evidence of foam cell and cholesterol crystal formation in macrophages incubated with oxidized LDL by fluorescence and electron microscopy. J Histochem Cytochem 1995;43:1071-1078.

13 Haley NJ, Shio H, Fowler S: Characterization of lipid-laden aortic cells from cholesterol-fed rabbits. I. Resolution of aortic cell populations by metrizamide density gradient centrifugation. Lab Invest 1977;37:287-296. 


\section{Cellular Physiology Cell Physiol Biochem 2015;37:419-431 \begin{tabular}{l|l} 
DOI: 10.1159/000430365 & (C) 2015 S. Karger AG, Basel
\end{tabular} and Biochemistry Published online: August 28, 2015

14 Bretscher MS, Munro S: Cholesterol and the Golgi apparatus. Science 1993;261:1280-1281.

15 Tangirala RK, Jerome WG, Jones NL, Small DM, Johnson WJ, Glick JM, Mahlberg FH, Rothblat GH: Formation of cholesterol monohydrate crystals in macrophage-derived foam cells. J Lipid Res 1994;35:93-104.

16 Warner GJ, Stoudt G, Bamberger M, Johnson WJ, Rothblat GH: Cell toxicity induced by inhibition of acyl coenzyme A:cholesterol acyltransferase and accumulation of unesterified cholesterol. J Biol Chem 1995;270:5772-5778.

17 Tabas I, Marathe S, Keesler GA, Beatini N, Shiratori Y: Evidence that the initial up-regulation of phosphatidylcholine biosynthesis in free cholesterol-loaded macrophages is an adaptive response that prevents cholesterol-induced cellular necrosis. Proposed role of an eventual failure of this response in foam cell necrosis in advanced atherosclerosis. J Biol Chem 1996;271:22773-22781.

18 Ross R: Cell biology of atherosclerosis. Annu Rev Physiol 1995;57:791-804.

19 Yao PM, Tabas I: Free cholesterol loading of macrophages induces apoptosis involving the fas pathway. J Biol Chem 2000;275:23807-23813.

20 Yao PM, Tabas I: Free cholesterol loading of macrophages is associated with widespread mitochondrial dysfunction and activation of the mitochondrial apoptosis pathway. J Biol Chem 2001;276:42468-42476.

21 Peled M, Fisher EA: Dynamic Aspects of Macrophage Polarization during Atherosclerosis Progression and Regression. Front Immunol 2014;5:579.

22 Chawla A: Control of macrophage activation and function by PPARs. Circ Res 2010;106:1559-1569.

23 Spann NJ, Garmire LX, Mcdonald JG, Myers DS, Milne SB, Shibata N, Reichart D, Fox JN, Shaked I, Heudobler D, Raetz CR, Wang EW, Kelly SL, Sullards MC, Murphy RC, Merrill AH, Jr., Brown HA, Dennis EA, Li AC, Ley K, Tsimikas S, Fahy E, Subramaniam S, Quehenberger O, Russell DW, Glass CK: Regulated accumulation of desmosterol integrates macrophage lipid metabolism and inflammatory responses. Cell 2012;151:138152.

24 Nguyen MT, Favelyukis S, Nguyen AK, Reichart D, Scott PA, Jenn A, Liu-Bryan R, Glass CK, Neels JG, Olefsky JM: A subpopulation of macrophages infiltrates hypertrophic adipose tissue and is activated by free fatty acids via Toll-like receptors 2 and 4 and JNK-dependent pathways. J Biol Chem 2007;282:35279-35292.

25 Hume DA, Gordon S: Optimal conditions for proliferation of bone marrow-derived mouse macrophages in culture: the roles of CSF-1, serum, Ca2+, and adherence. J Cell Physiol 1983;117:189-194.

26 Klapper M, Ehmke M, Palgunow D, Bohme M, Matthaus C, Bergner G, Dietzek B, Popp J, Doring F: Fluorescence-based fixative and vital staining of lipid droplets in Caenorhabditis elegans reveal fat stores using microscopy and flow cytometry approaches. J Lipid Res 2011;52:1281-1293.

27 Mori M, Itabe H, Higashi Y, Fujimoto Y, Shiomi M, Yoshizumi M, Ouchi Y, Takano T: Foam cell formation containing lipid droplets enriched with free cholesterol by hyperlipidemic serum. J Lipid Res 2001;42:1771-1781.

28 Zhang F, Xu M, Han WQ Li PL: Reconstitution of lysosomal NAADP-TRP-ML1 signaling pathway and its function in TRP-ML1(-/-) cells. Am J Physiol Cell Physiol 2011;301:C421-430.

29 Yin LM, Wei Y, Wang WQ, Wang Y, Xu YD, Yang YQ: Simultaneous application of BrdU and WST-1 measurements for detection of the proliferation and viability of airway smooth muscle cells. Biol Res 2014;47:75.

30 Fujisaka S, Usui I, Bukhari A, Ikutani M, Oya T, Kanatani Y, Tsuneyama K, Nagai Y, Takatsu K, Urakaze M, Kobayashi M, Tobe K: Regulatory mechanisms for adipose tissue M1 and M2 macrophages in diet-induced obese mice. Diabetes 2009;58:2574-2582.

31 Lawrence T, Natoli G: Transcriptional regulation of macrophage polarization: enabling diversity with identity. Nat Rev Immunol 2011;11:750-761.

32 Dewals BG, Marillier RG, Hoving JC, Leeto M, Schwegmann A, Brombacher F: IL-4Ralpha-independent expression of mannose receptor and Ym1 by macrophages depends on their IL-10 responsiveness. PLoS Negl Trop Dis 2010;4:e689.

33 Li X, Zhang Y, Xia M, Gulbins E, Boini KM, Li PL: Activation of Nlrp3 inflammasomes enhances macrophage lipid-deposition and migration: implication of a novel role of inflammasome in atherogenesis. PLoS One 2014;9:e87552.

34 Zhang F, Li PL: Reconstitution and characterization of a nicotinic acid adenine dinucleotide phosphate (NAADP)-sensitive Ca2+ release channel from liver lysosomes of rats. J Biol Chem 2007;282:25259-25269.

35 Zhang F, Jin S, Yi F, Li PL: TRP-ML1 functions as a lysosomal NAADP-sensitive Ca2+ release channel in coronary arterial myocytes. J Cell Mol Med 2009;13:3174-3185. 


\section{Cellular Physiology Cell Physiol Biochem 2015;37:419-431

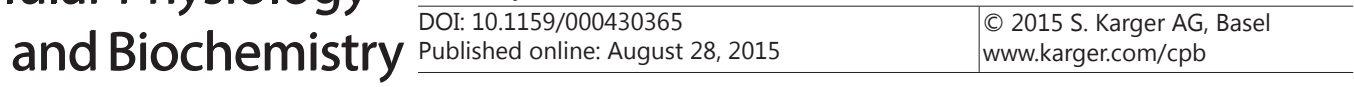 \\ Xu/Zhang/Li/Li/Zhang: Free Cholesterol and Macrophage Viability and Polarization}

36 Zhang F, Xia M, Li PL: Lysosome-dependent $\mathrm{Ca}(2+)$ release response to Fas activation in coronary arterial myocytes through NAADP: evidence from CD38 gene knockouts. Am J Physiol Cell Physiol 2010;298:C1209-1216.

37 Feig JE, Parathath S, Rong JX, Mick SL, Vengrenyuk Y, Grauer L, Young SG, Fisher EA: Reversal of hyperlipidemia with a genetic switch favorably affects the content and inflammatory state of macrophages in atherosclerotic plaques. Circulation 2011;123:989-998.

38 Feig JE, Rong JX, Shamir R, Sanson M, Vengrenyuk Y, Liu J, Rayner K, Moore K, Garabedian M, Fisher EA: HDL promotes rapid atherosclerosis regression in mice and alters inflammatory properties of plaque monocytederived cells. Proc Natl Acad Sci U S A 2011;108:7166-7171.

39 Huang WC, Sala-Newby GB, Susana A, Johnson JL, Newby AC: Classical macrophage activation up-regulates several matrix metalloproteinases through mitogen activated protein kinases and nuclear factor-kappaB.

PLoS One 2012;7:e42507.

40 Tiemessen MM, Jagger AL, Evans HG, Van Herwijnen MJ, John S, Taams LS: CD4+CD25+Foxp3+ regulatory T cells induce alternative activation of human monocytes/macrophages. Proc Natl Acad Sci U S A 2007;104:19446-19451.

41 Sun Y, Ishibashi M, Seimon T, Lee M, Sharma SM, Fitzgerald KA, Samokhin AO, Wang Y, Sayers S, Aikawa M, Jerome WG, Ostrowski MC, Bromme D, Libby P, Tabas IA, Welch CL, Tall AR: Free cholesterol accumulation in macrophage membranes activates Toll-like receptors and p38 mitogen-activated protein kinase and induces cathepsin K. Circ Res 2009;104:455-465.

42 Li H, Guo H, Li H: Cholesterol loading affects osteoblastic differentiation in mouse mesenchymal stem cells. Steroids 2013;78:426-433.

43 Wang M, Guo H, Wang S, Yang R, Li H, Zhao H, Wang S, Dong J, Chen W: The measurement of high-density lipoprotein mediated cholesterol efflux from macrophage cells by liquid chromatography tandem mass spectrometry. Cell Physiol Biochem 2014;34:1901-1911.

44 Yang Y, Lian YT, Huang SY, Yang Y, Cheng LX, Liu K: GABA and topiramate inhibit the formation of human macrophage-derived foam cells by modulating cholesterol-metabolism-associated molecules. Cell Physiol Biochem 2014;33:1117-1129.

45 Chang TY, Chang CC, Cheng D: Acyl-coenzyme A:cholesterol acyltransferase. Annu Rev Biochem 1997;66:613-638.

46 Shio H, Haley NJ, Fowler S: Characterization of lipid-laden aortic cells from cholesterol-fed rabbits. III. Intracellular localization of cholesterol and cholesteryl ester. Lab Invest 1979;41:160-167.

47 Robbins CS, Hilgendorf I, Weber GF, Theurl I, Iwamoto Y, Figueiredo JL, Gorbatov R, Sukhova GK, Gerhardt LM, Smyth D, Zavitz CC, Shikatani EA, Parsons M, Van Rooijen N, Lin HY, Husain M, Libby P, Nahrendorf M, Weissleder R, Swirski FK: Local proliferation dominates lesional macrophage accumulation in atherosclerosis. Nat Med 2013;19:1166-1172. 